\title{
INVESTIGANDO O ESFORÇO COGNITIVO, O CONHECIMENTO SOBRE TRADUÇÃO E A SATISFAÇÃO NA TRADUÇÃO LIBRAS-PORTUGUÊS
}

\author{
Norma Barbosa de Lima Fonseca ${ }^{1}$ \\ José Luiz Vila Real Gonçalves ${ }^{1}$ \\ Pedro Zampier ${ }^{1}$ \\ ${ }^{1}$ Universidade Federal de Ouro Preto, Mariana, Minas Gerais, Brasil
}

\begin{abstract}
Resumo: Este trabalho apresenta os resultados de um estudo exploratórioexperimental que utilizou rastreamento ocular, registro de ações de teclado e mouse, protocolos verbais retrospectivos livres, questionário prospectivo e questionário de satisfação como ferramentas metodológicas para as coletas e análises de dados. A fundamentação teórica apresenta aportes de diferentes áreas, como dos estudos empírico-experimentais com línguas de sinais (Emmorey, Thompson e Colvin, 2009; Wehrmeyer, 2014) e dos estudos processuais da tradução (Jakobsen e Jensen, 2008; Pavlović e Jensen, 2009; Hvelplund, 2017, dentre outros), que se apoiam em conceitos e princípios dos estudos da cognição. Os resultados obtidos e as análises e discussões desenvolvidas corroboram a validade e a produtividade do modelo de desenho experimental aplicado para abordar as questões em tela, além de trazerem contribuições relevantes para os ramos dos Estudos da Tradução em que se inserem e levantarem questionamentos para futuras pesquisas na área.

Palavras-chave: Pesquisas processuais em tradução; Tradução intermodal; Esforço cognitivo na tradução; Língua Brasileira de Sinais; Metodologias de pesquisa empírico-experimental em tradução
\end{abstract}




\title{
INVESTIGATING COGNITIVE EFFORT, KNOWLEDGE OF TRANSLATION, AND ASSESSMENT IN BRAZILIAN SIGN LANGUAGE-PORTUGUESE TRANSLATION TASKS
}

\begin{abstract}
This paper presents the results of an exploratory-experimental study that used eye-tracking, keylogging, free retrospective verbal protocols as well as prospective and satisfaction questionnaires as its main tools for collecting and analyzing data. The theoretical framework builds on different areas, such as empirical-experimental studies with sign languages (Emmorey, Thompson, and Colvin, 2009; Wehrmeyer, 2014) and translation process research (TPR) studies (Jakobsen and Jensen, 2008; Pavlović and Jensen, 2009; Hvelplund, 2017, among others), which are based on concepts and principles of cognitive studies. The results, discussions and analysis corroborate the validity and productivity of the model of the experimental-exploratory design adopted to address the issues under investigation, as well as to bring relevant contributions to the branches of Translation Studies in which they are inserted and to raise questions for future studies in the area.

Keywords: Translation Process Research; Intermodal Translation; Cognitive Effort in Translation; Brazilian Sign Language; EmpiricalExperimental Research Methods in Translation
\end{abstract}

\section{Introdução}

Os estudos processuais, como uma das subdivisões dos estudos descritivos da tradução, vêm se expandindo, se aprofundando e se consolidando nas duas últimas décadas, trazendo importantes contribuições teóricas e metodológicas, não só para esse ramo específico dos Estudos da Tradução, mas para as diversas disciplinas com as quais dialoga no campo dos estudos da linguagem e das ciências cognitivas. Dessa forma, este trabalho apresenta um estudo exploratório-experimental que aplica metodologias de investigação empírica a objetos de pesquisa voltados para o processo tradutório num contexto intermodal, isto é, de uma língua gestual-visual (a Libras) para uma língua vocal-auditiva (o português). Nesse aspecto, este trabalho explora um escopo relativamente pouco investi- 
gado até o momento, propondo avanços e contribuições teóricas, metodológicas e empíricas para as áreas em que se insere e com as quais dialoga.

O trabalho se constitui em torno do eixo metodológico das pesquisas empírico-experimentais voltadas para a investigação de aspectos do processo tradutório, utilizando as ferramentas de rastreamento ocular, para monitorar o processo de atenção visual dos participantes enquanto realizam as tarefas experimentais, de registro de ações no teclado e no mouse, técnica denominada em inglês como keylogging, por meio da qual se monitora a produção e edição dos textos-alvo, além da técnica de protocolos verbais retrospectivos, que serve como uma fonte adicional de dados sobre os processos de tomada de decisão e solução de problemas empreendidos pelos participantes e reportados após a finalização da tarefa. Foram utilizados, ainda, um questionário prospectivo, que serviu para verificar o perfil linguístico, acadêmico e profissional dos participantes, um questionário de conhecimento sobre tradução, para que fosse compreendida a perspectiva de tradução (PACTE, 2017) dos respondentes, e um questionário de satisfação e autoavaliação em relação à tradução produzida pelos participantes. Enquanto as primeiras ferramentas têm sido aplicadas largamente em diversos estudos experimentais desenvolvidos nos estudos processuais da tradução, com resultados relevantes para o avanço da compreensão dos fenômenos envolvidos, tendo as suas confiabilidade e validade reconhecidas e reiteradas, o questionário de satisfação tem sido pouco utilizado até então nos estudos processuais da tradução, podendo servir como mais um instrumento para triangulação de dados.

Mais especificamente, neste trabalho, pretendemos avaliar, por meio de um estudo exploratório-experimental, como indicadores de esforço cognitivo podem ser inferidos a partir dos dados de rastreamento ocular, o qual gera, dentre outras medidas pertinentes, a taxa de fixação (percentual do tempo total de fixações) e a duração média das fixações em diferentes áreas de interesse (AOIs, acrônimo em inglês para areas of interest) na tela do computador em que se realizam as tarefas experimentais. A partir de estudos 
anteriores da área (Jakobsen e Jensen, 2008; Pavlović e Jensen, 2009; Hvelplund, 2017, dentre outros), observa-se uma tendência de maior duração média de fixação e de tempo total de fixação na área do texto-alvo (na produção da tradução) em comparação com a área do texto-fonte (na leitura e compreensão desse texto). No entanto, algumas variáveis podem interferir nessa tendência, especialmente nos casos em que os participantes apresentam elevado grau de dificuldade com a leitura na língua-fonte, por questões de proficiência ou porque o gênero textual ou o tema do texto a ser traduzido é pouco familiar para tais participantes (Jakobsen e Jensen, 2008; Pavlović e Jensen, 2009). A direcionalidade também pode interferir nesse percentual, com aumento da duração média das fixações e do tempo total de fixações na área do texto-alvo ou do texto-fonte. Pretendemos, assim, avaliar o esforço cognitivo dedicado às diferentes áreas de interesse definidas para o desenho exploratório-experimental desta proposta e analisar algumas implicações teóricas e metodológicas para as pesquisas da área.

Este estudo investiga a influência da competência tradutória sobre o esforço cognitivo, a concepção de tradução (PACTE, 2017) e a satisfação subjetiva na realização de uma tarefa de tradução intermodal (Libras-português) realizada por diferentes perfis de participantes - tradutores e intérpretes de Libras-português (TILS) e bilíngues não tradutores. Tendo em vista o caráter inicial da pesquisa, a sessão experimental foi realizada com três participantes.

Além desta Introdução, este artigo inclui uma seção sobre estudos processuais da tradução, em que se destacam questões conceituais e metodológicas relativas ao uso de rastreamento ocular conjugado com algumas outras ferramentas de coleta de dados em pesquisas empírico-experimentais, especialmente nos Estudos da Tradução; em seguida, é apresentada uma breve discussão sobre pesquisas da área de línguas de sinais, especialmente com abordagens experimentais; a seção Metodologia detalha o desenho exploratório-experimental, sendo seguida pela Discussão dos resultados; a última seção, Considerações finais, apresenta as conclusões sobre este estudo e discute seus possíveis desdobramentos. 


\section{Estudos processuais da tradução e avanço de ferramentas metodológicas}

Os estudos processuais da tradução vêm se expandido e se consolidando com o desenvolvimento de novas ferramentas tecnológicas para a coleta e análise de dados empírico-experimentais. Desde os primeiros esforços de Krings (1986), que marcaram uma mudança de paradigma nos Estudos da Tradução, com o início da chamada vertente processual, a busca por metodologias que possibilitassem algum tipo de aproximação em relação aos processos cognitivos na tradução representam um desafio constante. Nessa fase inicial, que se estende até fins dos anos 1990, a utilização dos protocolos verbais (especialmente os concomitantes; Ericsson e Simon, 1980) foi a base metodológica para se inferirem alguns dos processos cognitivos implementados pelo tradutor, tendo dominado o cenário das pesquisas na área naquele período (Tirkkonen-Condit e Jääskeläinen, 2000).

Numa fase metodológica seguinte, a partir da segunda metade da década de 90, vem-se observando o avanço metodológico desse ramo dos estudos descritivos com a introdução do monitoramento da produção escrita através dos registros da atividade de teclado e mouse (keylogging), com destaque para o trabalho de Jakobsen (1999), que desenvolveu o programa Translog para essa finalidade. No início dos anos 2000, uma nova frente de recursos metodológicos é encampada pelos estudos processuais da tradução, na qual o acompanhamento minucioso da leitura e da atenção visual dos participantes passa a ser possível com significativa precisão e relativa facilidade, com o uso de equipamentos de rastreamento ocular. A inspiração para a nossa área de estudos vem do trabalho seminal de Just e Carpenter (1980), o qual fornece as bases para muitos dos conceitos e referências do que temos aplicado atualmente ao utilizar essa tecnologia, como a eye-mind assumption (princípio da ligação olho-mente), que defende que "o olho permanece fixado em uma palavra enquanto ela está sendo processada." (Just and Carpenter 330, tradução nossa). 
Em linhas gerais, pode-se afirmar que os protocolos de introspecção, com a predominância dos protocolos verbais concomitantes (protocolos de pensamento em voz alta ou think-aloud protocols, em inglês), constituíram a base dos estudos processuais nos anos 1980 até fins dos anos 1990, quando o recurso de keylogging passou a integrar os desenhos metodológicos de experimentos nesse ramo de estudos e, ao mesmo tempo, começou-se a questionar a interferência dos protocolos verbais concomitantes sobre os processos cognitivos sob investigação (Jakobsen, 2003). Passou-se então a utilizar principalmente os protocolos verbais retrospectivos, que envolvem comentários gerais ou específicos dos participantes de experimentos, agora não mais durante, mas logo após o término da tarefa experimental e com a observação de sua reprodução na tela do computador. Com o recurso de keylogging, juntamente com os protocolos retrospectivos, ampliou-se a precisão e a validade ecológica (proximidade de uma tarefa experimental em relação a uma tarefa real no universo profissional) com que era possível observar a produção e edição de uma tradução. No entanto, faltavam dados precisos sobre os processos de leitura, os quais, com a tecnologia de rastreamento ocular, passaram a ser coletados em alguns centros de pesquisa que investigavam (e ainda investigam) os processos tradutórios, com destaque para o CRITT (Centre for Research and Innovation in Translation and Translation Technology), da Copenhagen Business School, na Dinamarca, e o LETRA (Laboratório Experimental de Tradução), da UFMG, no Brasil. Como mencionado anteriormente, Just e Carpenter (1980), em estudo seminal sobre padrões de fixação na leitura, demonstraram que, dependendo dos fatores envolvidos nos segmentos textuais fixados (familiaridade com o tema do texto, frequência dos itens lexicais etc.), era possível observar uma variação significativa na duração média das respectivas fixações.

Dentre os diversos estudos que utilizam dados de rastreamento ocular para investigar o esforço cognitivo nas pesquisas processuais dos Estudos da Tradução, Pavlović e Jensen (2009) destacam-se ao analisar diferentes indicadores de esforço cognitivo (tempo total 
das fixações, a duração média das fixações, o tempo total da tarefa e a dilatação da pupila) de estudantes e tradutores profissionais durante a execução de tarefas de tradução para a primeira língua (L1) e para a segunda língua (L2) de duas resenhas de livros sobre política publicadas em jornais no par linguístico dinamarquês-inglês. Nessa análise, os autores investigam as diferenças entre o processo tradutório dessas duas tarefas em ambos os grupos de participantes.

Dado o escopo do presente artigo, destacamos apenas os resultados da duração média das fixações (em milissegundos) e do tempo total das fixações na tradução para L2 (em segundos), a partir da única hipótese comprovada por Pavlović e Jensen (2009), qual seja, o processamento do texto-alvo (TA) requer maior dispêndio de esforço cognitivo que o processamento do texto-fonte (TF) em ambas as direções (inglês $<=>$ dinamarquês), por todos os três indicadores relevantes do estudo (tempo total das fixações, a duração média das fixações e a dilatação da pupila). Esse maior dispêndio no TA representou um aumento de 55,1\% na comparação da duração média das fixações no TF $(247 \mathrm{~ms})$ com a das fixações no TA (383 ms). Com relação ao tempo total das fixações, esse aumento foi de $118 \%$ no TA (379 ms) na comparação com o TF (174 ms). Desse modo, dois diferentes indicadores de esforço cognitivo apontam que é na produção de um texto na língua-alvo que os participantes despendem mais esforço cognitivo.

Hvelplund (2017) realizou um experimento que analisou a alocação e a coordenação de esforço cognitivo por sete estudantes de pós-graduação em Tradução na execução de uma tarefa de tradução para dublagem. Durante esse processo de produção do TA, de acordo com o autor, os participantes precisavam coordenar informações a partir de três fontes distintas (um excerto do texto-fonte em inglês, com 284 palavras, o vídeo de um desenho animado canadense, com cerca de 2 minutos, e um dicionário) e do próprio texto-alvo sendo produzido para gravação por atores em um estúdio. Além de investigar o fluxo de processamento e a distribuição de atenção, Hvelplund (2017) analisou a duração média das fixações e o tamanho da pupila como indicadores de esforço cognitivo. 
Semelhante ao que foi constatado nos estudos mencionados anteriormente, a maior duração média das fixações foi no TA, sendo esta de $290 \mathrm{~ms}$, enquanto a duração no TF foi de $208 \mathrm{~ms}$, no dicionário foi de $224 \mathrm{~ms}$ e no vídeo foi de $285 \mathrm{~ms}$. Desse modo, mesmo em uma tarefa que continha outros elementos na tela, além do texto-fonte e do texto-alvo, o maior esforço observado continuou sendo no texto-alvo.

Portanto, a realização deste estudo exploratório, que visa investigar o processo tradutório entre duas diferentes modalidades linguísticas (gestual-visual e vocal-auditiva), conforme descreveremos na seção metodológica deste trabalho, pode contribuir para os estudos processuais à medida que busca fornecer evidências sobre padrões de dispêndio de esforço nesse tipo de tarefa.

Na próxima seção, apresentaremos alguns aspectos gerais sobre línguas de sinais, além de estudos experimentais com essa modalidade linguística.

\section{Libras e estudos sobre línguas de sinais}

Libras é a sigla de Língua Brasileira de Sinais, que ocupa hoje o status de língua oficial das comunidades surdas do Brasil. Essa conquista foi regulamentada com a Lei 10.436 , de 24 de abril de 2002, que reconheceu a Libras como "meio legal de comunicação e expressão [...] e outros recursos de expressão a ela associados." (BRASIL 23). Ainda no art. $1^{\circ}$ dessa Lei, a Libras é definida como

a forma de comunicação e expressão, em que o sistema linguístico de natureza visual-motora, com estrutura gramatical própria, constitui um sistema linguístico de transmissão de ideias e fatos, oriundos de comunidades de pessoas surdas do Brasil. (BRASIL 23) 
Assim como ocorre com as línguas vocais-auditivas, a Libras está integrada no contexto dos estudos linguísticos, sendo objeto de estudo de diferentes pesquisadores brasileiros, dentre eles Quadros e Karnopp (2004), que trazem ao leitor conhecimento sobre a fonologia, a morfologia e a sintaxe da Libras. Nessa obra, as autoras discutem aspectos da Libras, como, por exemplo, iconicidade e arbitrariedade dos sinais, parâmetros (configuração de mão, locação da mão, movimento da mão, orientação da mão e aspectos não-manuais), formação do léxico, flexão, sintaxe de concordância etc.

Apesar de haver diferentes estudos sobre a Libras, não há referência de estudos experimentais com uso de rastreamento ocular sobre essa língua até onde sabemos. Mesmo em outras línguas de sinais, há ainda poucos estudos que se beneficiam desse tipo de tecnologia, como os de Emmorey, Thompson e Colvin (2009) e Wehrmeyer (2014).

Emmorey, Thompson e Colvin (2009) utilizaram um rastreador ocular montado na cabeça, fabricado pela SensoMotoric Instruments, para determinar se o padrão de comportamento do olhar era influenciado pelo conteúdo das informações. Para atingir esse objetivo, nove participantes surdos, usuários da ASL (American Sign language - Língua Americana de Sinais) como L1 e 10 participantes ouvintes, aprendizes/iniciantes na ASL como L2, prestaram atenção em uma narrativa curta simples e uma descrição do layout de uma cidade, ambas produzidas ao vivo por um dos cinco sinalizantes fluentes na ASL que participaram da pesquisa de Emmorey, Thompson e Colvin (2009). A narrativa e a descrição se diferenciaram na quantidade de palavras soletradas manualmente e no número de construções com classificadores locativos, com base na pressuposição de que esses fatores afetariam a região para onde os participantes olhariam a fim de compreenderem o sinal. Outra pressuposição das autoras era de que haveria a tendência de os participantes desviarem o olhar do rosto para as mãos dos sinalizantes em construções com classificadores locativos por dois motivos: "porque a localização da(s) mão(s) no espaço transmite informações semânticas críticas 
e porque os sinalizantes olham com frequência para suas próprias mãos ao produzirem [essas] construções [...]" (Emmorey; Thompson and Colvin 238, tradução nossa).

Além disso, a hipótese das autoras era de que os padrões de fixação ocular poderiam indicar a dificuldade de processamento da língua de sinais. Para testar essa hipótese, as autoras calcularam a porcentagem de tempo que os participantes fixaram no rosto do sinalizante ou próximo dele. De maneira específica, Emmorey, Thompson e Colvin (2009) calcularam a média percentual de tempo de fixação em diferentes áreas do rosto (face superior, olhos, boca e face inferior).

A última análise das autoras concentrou-se em investigar o foco de atenção do participante quando esse afastava o olhar do rosto para as mãos ou para o corpo do sinalizante. Para isso, as autoras criaram um código para indicar o tipo de sinal ou ação que o sinalizante estava fazendo quando havia desvio do olhar por parte do participante: (a) um sinal lexical, (b) uma soletração manual ou (c) um sinal classificador, e se o sinalizante estava autofixando o sinal, ou seja, aqueles sinais ou "gestos nos quais o falante olha para sua(s) própria(s) mão(s)." (Emmorey; Thompson and Colvin 238, tradução nossa). Desse modo, o estudo analisou o local específico da fixação no rosto (olhos ou próximo deles, boca ou testa), a frequência com que os participantes desviavam o olhar do rosto para a mão ou corpo do sinalizante e o conteúdo que estava sendo sinalizado quando essa mudança de olhar ocorria.

Apesar da diferença de proficiência entre os grupos de participantes, as autoras concluíram que ambos os grupos fixaram o olhar principalmente no rosto do sinalizante (mais de $80 \%$ do tempo), mas em locais distintos. Enquanto os participantes ouvintes fixaram na boca ou próximo à boca do sinalizante, os participantes surdos tinham a tendência de fixar nos olhos ou perto deles. A porcentagem média de tempo variou entre os participantes dos dois grupos, mas não pelo tipo de texto (narração ou descrição). Sendo assim, tanto os participantes surdos quanto os ouvintes fixaram no rosto do sinalizante cerca de $95 \%$ do tempo na narração e pouco mais de $80 \%$ na descrição. 
Além disso, Emmorey, Thompson e Colvin (2009) indicam que, embora os participantes ouvintes tenham afastado o olhar do rosto do sinalizante com mais frequência que os participantes surdos, o padrão de mudança de olhar foi semelhante para ambos os grupos. Segundo as autoras, quando uma mudança de olhar ocorria, o sinalizante quase sempre estava olhando para as próprias mãos e geralmente estava produzindo uma construção com classificadores. A partir dessas constatações, as autoras concluem que a atenção visual conjunta e a atenção aos movimentos da boca (no caso dos participantes ouvintes) são os fatores que afetam os padrões de fixação do olhar durante a compreensão da língua de sinais, e não a complexidade linguística ou carga de processamento.

Utilizando um rastreador ocular Tobii T60, Wehrmeyer (2014) analisa os padrões de hábitos de visualização de 11 participantes surdos, o grupo experimental, e 18 participantes ouvintes, o grupo controle, enquanto eles assistiam a um vídeo de 10 minutos com três excertos de notícias interpretadas na SASL (South African Sign Language, Língua Sul-africana de Sinais).

Para testar a hipótese de que a principal fonte de informação dos participantes surdos é o intérprete, mas que eles usam significativamente outras fontes de informação quando não o compreendem, foram criadas quatro áreas de interesse (Intérprete, Filme, Texto e Bocas), tendo sido perguntado aos participantes surdos se eles haviam entendido o intérprete. A área de interesse Intérprete refere-se ao intérprete do canal de notícias que aparecia junto ao repórter no vídeo. A área Filme se refere ao vídeo com os três excertos de notícias, enquanto a área Texto inclui os textos legíveis que apareciam na tela, como legendas e resultados esportivos, mas exclui aqueles integrados no filme principal, como excertos de documentos e indicadores financeiros. A autora também menciona uma quinta área de interesse, Outros, que abrange todas as áreas que não são aquelas mencionadas, como logotipo, relógio, imagem de fundo e olhares fora da tela.

A autora destaca resultados das três primeiras áreas, os quais apontam que o principal foco dos espectadores surdos é no Intér- 
prete (mais no rosto, incluindo a boca, do que nas mãos), com a duração média de fixações (DMF) de $840 \mathrm{~ms}$, seguido do Filme $(\mathrm{DMF}=253 \mathrm{~ms})$ e das legendas $(\mathrm{DMF}=182 \mathrm{~ms})$. O foco dos espectadores ouvintes, por sua vez, é também no Intérprete (DMF $=417 \mathrm{~ms})$ e no Filme $(\mathrm{DMF}=403 \mathrm{~ms})$, mas eles também fixam o olhar no Texto $(\mathrm{DMF}=277 \mathrm{~ms})$.

Outra medida gerada pelo rastreamento ocular, a duração total das visitas, também indica que a distribuição de atenção entre os dois grupos de participantes nessas três áreas é bem diferente. Em termos percentuais com relação ao tempo de duração do vídeo (580 s), os participantes ouvintes ficaram $70 \%$ do tempo visualizando o Filme, mas também dividiram sua atenção no Texto (14\%) e no Intérprete (12\%). Em relação aos participantes surdos, assim como ocorreu com a duração média das fixações, houve maior distribuição de atenção no Intérprete (75\%), depois no Filme (18\%) e por último no Texto $(5 \%)$. Entretanto, uma menor atenção é dada à área de interesse Outros, em que a duração total das visitas ficou em $4 \%$ para os participantes ouvintes e $2 \%$ para os participantes surdos. A partir desses resultados, a autora conclui que houve comprovação da hipótese de que a principal fonte de informações para os surdos é o intérprete, apesar de, exceto pelo filme, as outras fontes de informação visual terem sido praticamente excluídas, independentemente de os participantes terem compreendido ou não o intérprete.

Visando preencher uma lacuna de estudos experimentais que investigam a Libras e sua tradução para o português, apresentaremos os aspectos metodológicos deste estudo na próxima seção.

\section{Metodologia}

Como Alves (2003) argumenta, uma vez que os processos cognitivos envolvidos na tradução não são acessíveis à observação direta, é necessário utilizar o princípio da triangulação de ferramentas metodológicas para coletar e analisar os dados de pesquisa a fim de que se aproxime de um quadro mais realista e menos enviesado 
do fenômeno que se pretende estudar. Assim, este estudo aplicou a triangulação de diferentes recursos metodológicos com a finalidade de aprofundar a compreensão sobre aspectos dos processos cognitivos na tradução intermodal Libras-português, visando, assim, contribuir para a expansão dos estudos processuais da tradução.

\subsection{Desenho experimental}

O desenho experimental desta pesquisa foi construído com o objetivo de se obterem dados que permitissem verificar as hipóteses de que, em uma tarefa experimental, os participantes com competência tradutória (CT) mais desenvolvida apresentariam (i) uma perspectiva de tradução mais dinâmica do que estática (PACTE, 2017); (ii) uma maior satisfação em relação ao produto de sua tradução; e (iii) um menor dispêndio de esforço cognitivo na execução dessa tarefa de tradução. Ressalta-se que essas hipóteses são apenas exploratórias, dado o tamanho da amostra de participantes da pesquisa aqui relatada. As mesmas serão verificadas e eventualmente reformuladas em um estudo mais aprofundado sobre o tema e com mais participantes (Zampier, 2019).

Para verificar a viabilidade dessas hipóteses, três participantes com diferentes perfis realizaram uma tarefa experimental de tradução de um vídeo em Libras para o português escrito. Os dados dessa tarefa foram coletados no Laboratório Experimental de Estudos da Linguagem (LEXEL) do Instituto de Ciências Humanas e Sociais (ICHS) da UFOP, buscando-se manter ao máximo a validade ecológica durante as coletas e proporcionar conforto e privacidade aos participantes.

Para a realização do experimento, diferentes ferramentas metodológicas foram utilizadas. Inicialmente, os participantes preencheram um questionário prospectivo de perfil, que visava obter dados sobre seu perfil pessoal, linguístico, acadêmico e profissional. Em seguida, os participantes responderam a um questionário de conhecimento sobre tradução em português, adaptado do questionário em inglês utilizado por PACTE (2017), que continha 
sentenças afirmativas em relação às quais deveriam assinalar sua concordância completa, concordância, discordância ou discordância completa. Esse questionário visa fornecer informações sobre a perspectiva de tradução dos respondentes e, conforme descreve PACTE (2017), das 27 afirmativas, 12 eram relacionadas a uma perspectiva dinâmica de tradução - voltada para o texto e indicadoras de uma abordagem mais funcional de tradução enquanto as outras 15 eram indicativas de um conceito estático de tradução - voltado para as palavras e com uma abordagem mais literal de tradução. Os autores destacam ainda que as perguntas do questionário abarcam

\begin{abstract}
[...] sete fatores relacionados ao conhecimento sobre tradução: unidades de tradução; problemas de tradução; fases do processo de tradução; métodos de tradução; procedimentos (estratégias e técnicas etc.); funções do brief e do público-alvo; e conceito de tradução e competência tradutória. (PACTE 133, tradução nossa).
\end{abstract}

As instruções fornecidas aos participantes para a execução da tarefa orientavam que a tradução deveria ser feita para o português escrito a fim de ser disponibilizada no site institucional de um curso de graduação em Letras. Os participantes também foram informados de que não poderiam acessar nenhum material de apoio e que teriam o tempo que precisassem para concluir a tarefa.

Para realizá-la, foram utilizados um rastreador ocular e um programa de registro do processo de produção do texto-alvo. $\mathrm{O}$ rastreador ocular Tobii TX300 registra os movimentos oculares, incluindo as fixações, e o programa Translog II, por sua vez, registra o acionamento de teclado e mouse.

Após a realização da tarefa, os participantes foram solicitados a comentar sobre a tradução realizada. Com o apoio da reprodução da tarefa no Translog, os participantes comentaram livremente sobre diferentes aspectos do processo tradutório, como problemas de 
tradução, soluções encontradas, dificuldades e facilidades durante a execução da tarefa. Esses dados podem fornecer indícios sobre processos cognitivos que ocorrem durante a realização de atividades como uma tradução e que são caros às discussões abordadas neste trabalho, especialmente por darem indícios sobre processos de tomada de decisão, solução de problemas e inferências em geral.

Por último, foi solicitado aos participantes que preenchessem um questionário de satisfação com relação à tarefa de tradução realizada. O objetivo do questionário era identificar, além da satisfação dos participantes e da expectativa em relação ao nível de satisfação do leitor com o texto-alvo produzido, os problemas de tradução, as soluções encontradas e a importância dada ao público -alvo ao se traduzir um vídeo da Libras para o português.

Na próxima seção, discutiremos os resultados desse estudo exploratório-experimental.

\section{Resultados e discussão}

Os resultados apresentados nesta seção foram obtidos por meio do questionário prospectivo de perfil, do questionário de conhecimento sobre tradução, dos dados gerados pelo rastreador ocular Tobii TX300, dos protocolos retrospectivos livres e do questionário de satisfação com a tradução realizada. Ressaltamos que as análises efetuadas dos dados de rastreamento ocular se concentram em medidas de esforço cognitivo, quais sejam, o número, a duração média das fixações e o tempo total das fixações, e se referem aos dados do participante P02. Os dados de rastreamento ocular dos demais participantes (P01 e P03) não foram analisados neste trabalho por terem tido o percentual de captura de rastreamento ocular abaixo de $70 \%$, o que coloca em questão a sua validade para o estudo dos processos em foco (O’Brien, 2009). 


\subsection{Experiência e formação acadêmica dos participantes}

As informações fornecidas pelos participantes quando preencheram o questionário de perfil foram utilizadas para determinar a experiência deles como tradutores e intérpretes de Libras-português e o tipo de formação acadêmica que possuíam. O participante 1 (P01) atua como docente de língua brasileira de sinais (Libras) e atuou profissionalmente como intérprete de Libras-português por mais de 10 anos, cursa doutorado na área de estudos linguísticos e tem a Libras e o português como L1; o participante 2 (P02), estudante de Letras-inglês, com fluência elementar em Libras, tem o português como L1 e a Libras como L2; o participante 3 (P03), formado em Letras, com fluência profissional limitada em Libras, tem o português como L1 e a Libras como L2.

\subsection{O conhecimento sobre tradução}

A partir do questionário de conhecimento sobre tradução, são obtidos dois indicadores: o Índice Dinâmico de Conhecimento sobre Tradução (IDCT) e o Coeficiente de Coerência do Conhecimento sobre Tradução (CCCT). O IDCT permite, segundo PACTE (2017), identificar se o conhecimento implícito sobre tradução de um respondente tem mais características dinâmicas ou estáticas. O cálculo do CCCT, por sua vez, permite determinar se o conceito dos diferentes fatores envolvidos na tradução é consistentemente dinâmico ou estático.

Para calcular o IDCT e o CCCT, conforme orienta PACTE (2017), consideramos a pontuação total de cinco pares de itens do questionário ( 3 e 24,10 e 4, 23 e 11, 14 e 5, 27 e 16). A pontuação para cada resposta é a seguinte: concordo completamente $=4$; concordo $=3$; discordo $=2$; discordo completamente $=1$.

Para o cálculo do IDCT, uma pontuação foi conferida a cada um dos itens dos pares destacados. Posteriormente, um valor pré-estabelecido $(1 ; 0,5 ; 0 ;-0,5$ ou -1) foi atribuído a cada um dos pares de itens (PACTE, 2017). Foi calculada então a média dos valores 
obtidos conforme o valor conferido a cada um dos pares e, assim, obtiveram-se os valores de IDCT dos participantes de nossa pesquisa, conforme indicados na Tabela 1, a seguir.

Para o cálculo do CCCT, utiliza-se a mesma pontuação para as respostas dadas aos pares de itens. Posteriormente um rótulo pré -estabelecido (Dinâmico/Estático, Dinâmico ou Estático) (PACTE, 2017) foi conferido a cada um dos pares. Foi calculado então o total de itens Dinâmicos e o total de itens Estáticos para cada item dos pares, sendo que o rótulo Dinâmico/Estático conferia 1 ponto para os itens Dinâmicos e 1 ponto para os itens Estáticos. A maior soma (Dinâmico ou Estático) é subtraída da menor soma (Dinâmico ou Estático). À pontuação final obtida é conferido um Coeficiente de Coerência que pode ser 1 ou "totalmente consistente", para uma pontuação de 4 ou $5 ; 0,5$ ou "consistência intermediária", para uma pontuação de 2 ou 3; e 0 ou "totalmente inconsistente", para uma pontuação de 0 ou 1 . Os resultados dos cálculos de IDCT e de CCCT dos nossos participantes são reproduzidos no Quadro 1.

Quadro 1 - IDCT e CCCT dos participantes

\begin{tabular}{|l|l|l|}
\hline Participantes & IDCT & CCCT \\
\hline P01 & 0,10 & Totalmente inconsistente \\
\hline P02 & 0,20 & Consistência intermediária \\
\hline P03 & 0,20 & Consistência intermediária \\
\hline
\end{tabular}

Fonte: Elaborado pelos autores.

Conforme o Quadro 1, P02 e P03 possuem o maior IDCT $(0,20)$ e P01 o menor $(0,10)$. Apesar da diferença entre os resultados, com base em PACTE (2017), todos os nossos participantes possuem uma tendência à perspectiva tradutória dinâmica, uma vez que os três apresentam um "[...] grau de dinamismo acima de zero [...]” (PACTE 137, tradução nossa). 
Ao considerarmos a experiência de atuação como TILS, uma das variáveis que poderia influenciar os resultados, verificamos que P01 atuou por mais de 20 anos nessa área. No entanto, seu grau de dinamismo é menor do que o de P02 e de P03, sendo que P02 nunca atuou como TILS e P03 já atuou por quatro meses.

Uma das possíveis justificativas para esse maior grau de P02 é o fato de que o participante está cursando ou já cursou disciplinas na graduação, como "Teoria da tradução", "Metodologia da tradução", "Tradução de textos gerais" e "Tradução de Libras". Apesar de P02 afirmar em sua retrospecção que "[...] muitas das vezes que eu voltei no vídeo foi porque tinha algum sinal que eu não entendi direito ou porque eu realmente não sabia [...]", ele complementa sua fala e justifica que fazia isso com o intuito de "[...] entender o vídeo inteiro para [...] poder fazer a tradução." Conforme afirma PACTE (132), essa percepção da importância do texto como um todo para a tradução é um dos indicativos de uma perspectiva de tradução mais dinâmica. Outro indicativo dessa perspectiva - voltada para o sentido do texto - , expressado por P02, é a constatação de que, apesar de que seu texto-alvo foi sendo construído a partir de trechos digitados de forma esparsa, a "[...] tentativa [é] de construir um sentido para aquilo". O maior grau de dinamismo de P02 é evidenciado no final do seu próprio relato:

\begin{abstract}
[...] o que eu percebo muito na tradução que eu fiz é que eu tento compreender o vídeo para depois fazer uma tradução da melhor forma possível, tentando levar o sentido do vídeo [...] alguns sinais que eu realmente pulei porque eu não sabia, mas imaginei que pelo contexto geral do vídeo faria sentido mesmo sem aquele sinal [...] (Excerto do protocolo de P02).
\end{abstract}

O participante acrescenta ainda que a dificuldade foi muito mais "[...] não saber os sinais [...]" do que de fato produzir o texto-alvo. Isso indicia que o participante apresenta, ao menos, uma com- 
preensão do texto-fonte, apesar de considerar que sua fluência em Libras é elementar.

Em seus relatos, P01 afirma que se preocupou primeiramente em compreender os sinais do texto-fonte e destacou que dividiu a sua tradução em duas partes, uma vez que o vídeo abordava dois temas. Após ter compreendido o assunto principal do vídeo, ela organizou o texto escrito a partir dos dois temas. Essas observações nos parecem específicas de uma perspectiva mais dinâmica de tradução, como salienta PACTE (2017), ou seja, voltada para a compreensão do texto como um todo, mesmo que P01 tenha apresentado um IDCT menor que os outros dois participantes e possuir um Coeficiente de Coerência totalmente inconsistente.

Apresentando o mesmo IDCT de P02, P03 afirma que "[...] repetia o vídeo, parava, tentava escrever [...]". Relata ainda que, em determinado momento de incompreensão do texto-fonte, “[...] pulei uma parte do vídeo. Quando eu percebi que não estava dando certo eu ficar numa parte [...] eu pulei para ver se eu conseguia juntar a informação e construir uma sentença.". Diferentemente dos relatos dos outros participantes, nos relatos de P03, é possível observar que ele enfatizou bastante os problemas de tradução encontrados e a segmentação do texto-fonte: “[...] fui lá para outra parte que fala dos intérpretes [...] adiantei o vídeo lá para baixo pois vi que o final eu estava conseguindo entender com mais facilidade [...] voltei na parte que eu estava tendo um pouquinho de problema [...]". Uma possível confirmação desse enfoque na segmentação do texto-fonte para a produção do texto-alvo poderia ser obtida com a investigação das unidades de tradução, o que não desenvolveremos neste trabalho dado o escopo do estudo em questão. Ao finalizar seu relato, P03 reafirma a importância que dá ao paralelismo de significados entre o vídeo e a tradução: “[...] finalizando o texto, revendo o vídeo para poder certificar que era aquilo mesmo que eu estava tentando escrever [...]" e ainda "[...] eu volto [...] assisti o vídeo para ver se realmente é aquilo [...]".

Assim, P01, apesar de sua vasta experiência profissional como TILS, apresentou um IDCT menor do que o IDCT de P02 e P03, 
os quais não possuem esse tipo de experiência profissional. Quanto ao CCCT, P01 é totalmente inconsistente, enquanto P02 e P03 têm uma consistência intermediária. Em ambos os índices, IDCT e CCCT, contrariamente às nossas pressuposições iniciais, P02 e P03 apresentam um IDCT e um CCCT maior do que os de P01. Portanto, faz-se necessário discutir mais a fundo as implicações e a validade de tais parâmetros em futuros trabalhos da área.

\subsection{O nível de satisfação com a tradução}

Quanto ao nível de satisfação com a tradução produzida pelo participante e à expectativa do nível de satisfação do público-alvo leitor da tradução, apresentamos os resultados dos três participantes:

Quadro 2 - Nível de satisfação com a tradução

\begin{tabular}{|l|l|l|}
\hline Participantes & $\begin{array}{l}\text { Nível de satisfação } \\
\text { do participante com } \boldsymbol{a} \\
\text { tradução }\end{array}$ & $\begin{array}{l}\text { Expectativa do nível de } \\
\text { satisfação do público-alvo } \\
\text { da tradução }\end{array}$ \\
\hline P01 & $\begin{array}{l}\text { Nem insatisfeito nem } \\
\text { satisfeito }\end{array}$ & Satisfeito \\
\hline P02 & $\begin{array}{l}\text { Nem insatisfeito nem } \\
\text { satisfeito }\end{array}$ & $\begin{array}{l}\text { Nem insatisfeito nem } \\
\text { satisfeito }\end{array}$ \\
\hline P03 & Satisfeito & Satisfeito \\
\hline
\end{tabular}

Fonte: Elaborado pelos autores.

Dentre os participantes, P03 foi o que demonstrou o nível mais alto de satisfação com a tradução realizada. Essa satisfação (Satisfeito), segundo ele, deve-se ao fato de ter conseguido "[...] captar as informações, pois aos poucos consegui associar os sinais e não fiquei preso em uma parte específica do vídeo por causa de um sinal ou outro. Busquei entendimento total para depois analisar com mais atenção os detalhes." Quanto à expectativa do nível de satisfação do público-alvo (Satisfeito), P03 afirma que “[a] tradução não 
ficou perfeita, mas acredito que eu tenha conseguido apresentar o conteúdo proposto no vídeo". Caso pudesse refazer sua tradução, P03 afirma ainda que "[...] poderia ter feito outras escolhas linguísticas para apresentar um texto mais formal."

P01, por sua vez, afirma, ao justificar seu nível de satisfação com a tradução realizada (Nem insatisfeito nem satisfeito), que é "[...] difícil considerar excelente num processo de tradução, sempre tem aspecto a melhorar." Com relação à expectativa do nível de satisfação do público-alvo (Satisfeito), P01 afirma que a clareza é o principal motivo para seus leitores ficarem satisfeitos com o texto, mas destaca a importância de "conferir e reconferir", caso pudesse refazer a tradução.

Para P02, a justificativa para o seu nível de satisfação com a tradução (Nem satisfeito nem insatisfeito) seria o seu nível de conhecimento da Libras, por isso "[...] não seria possível uma tradução melhor ou mais detalhada [...]". Ele indica ainda que "[...] parece ter conseguido captar algum sentido do vídeo [...]”, mas que a insatisfação é devida à "[...] precisão da tradução." Quanto ao nível de satisfação de seu leitor, P02 indica Nem satisfeito nem insatisfeito e afirma que esse nível “[...] dependerá do conhecimento ou não do meu leitor, em relação a Libras e/ou em relação à concepção de tradução que meu leitor terá”, apontando que “[...] alguns sinais não foram traduzidos podendo gerar sensação de ser uma tradução incompleta."

\subsection{0 esforço cognitivo}

Como relatado anteriormente, são apresentados apenas os resultados de esforço cognitivo de P02, com base nas medidas de rastreamento ocular, as quais, conforme sugerido por Hvelplund (2014), podem ser obtidas a partir dos dados de fixação, especificamente o total de fixações, a duração média das fixações e o tempo total das fixações. As áreas de interesse analisadas foram a região do texto-fonte (vídeo em Libras) e a tela do Translog, na qual foi produzido o texto-alvo em língua portuguesa. 
Como afirma Hvelplund ((B) 112, tradução nossa), a compreensão de um vídeo, envolve a “[...] coordenação de informações de diversos canais e deve, portanto, muito provavelmente, demandar mais esforço cognitivo [...]". Como em nossa investigação o textofonte apresentado aos participantes é um vídeo em uma língua de modalidade gestual-visual, ou seja, a informação do texto-fonte está disponibilizada não na forma escrita, mas, sim, sinalizada em vídeo, acreditamos que haverá também a coordenação de informações de diversos canais e, portanto, mais esforço cognitivo no texto-fonte (vídeo) em comparação com o esforço cognitivo no texto-alvo. Assim sendo, apresentamos os resultados de alocação de esforço cognitivo de P02 durante a execução da tarefa de tradução, com base no número, na duração média e no tempo total das fixações.

Tabela 1 - Medidas de fixações de P02

\begin{tabular}{|c|c|c|c|}
\hline Área de interesse & $\begin{array}{l}\text { Número de } \\
\text { fixações }\end{array}$ & $\begin{array}{l}\text { Duração média } \\
\text { das fixações (ms) }\end{array}$ & $\begin{array}{l}\text { Tempo total das } \\
\text { fixações (s) }\end{array}$ \\
\hline $\begin{array}{l}\text { Texto-fonte (vídeo } \\
\text { em Libras) }\end{array}$ & 2.707 & 599 & $1.622,64$ \\
\hline Texto-alvo & 1.319 & 383 & 505,52 \\
\hline
\end{tabular}

Fonte: Elaborada pelos autores.

Nessa tabela, é possível observar que P02 teve uma maior alocação de esforço cognitivo no texto-fonte se considerarmos os três parâmetros destacados. O número de fixações (2.707), a duração média das fixações (599 ms) e o tempo total das fixações $(1.622,64$ s) confirmam que houve mais fixações e que elas permaneceram por mais tempo no texto-fonte.

Os resultados obtidos corroboram alguns dos resultados de Jakobsen e Jensen (2008). Os autores identificaram que, diferentemente de tradutores profissionais, os estudantes de tradução, assim como P02, têm mais fixações e dedicam mais esforço à leitura e à interpretação do texto-fonte em tarefas de tradução escrita de L2 para L1. Apesar de o texto-fonte da pesquisa aqui relatada ser um 
vídeo (que efetivamente se trata de um texto em Libras), acreditamos que essas comparações entre os resultados são pertinentes.

Ao contrário dos resultados encontrados em nossa investigação com o texto-fonte em vídeo, os resultados de Pavlović e Jensen (2009) e de Hvelplund (2011) apontaram que tanto tradutores profissionais como estudantes de tradução apresentam mais esforço cognitivo nos textos-alvo do que nos textos-fonte em tarefas de tradução escrita.

$\mathrm{Na}$ análise de esforço cognitivo realizada por Hvelplund (2017), o resultado de dilatação de pupila evidenciou maior esforço cognitivo no vídeo, enquanto o resultado da duração média de fixações, o qual também é utilizado aqui, apontou maior esforço no texto-alvo (290 ms), com um valor bem próximo à duração média das fixações no vídeo (285 ms). Em nossa pesquisa, embora utilizando dois indicadores diferentes dos de Hvelplund (2017), todas as medidas de fixações utilizadas apontaram maior esforço no texto-fonte, que também é um vídeo de texto sinalizado, em comparação com o texto-alvo, ou seja, o maior esforço no vídeo de Libras foi confirmado por todas as medidas de fixações no nosso estudo e em Hvelplund (2017) pela dilatação da pupila. No entanto, tal resultado vai ao encontro especialmente dos de Wehrmeyer (2014), em que há uma elevação significativa para a duração média da fixação na leitura de vídeo de língua de sinais (ainda que não tenha sido a Libras). Aqui, parece haver um indício de que a leitura de línguas gestuais-visuais envolve um padrão de esforço cognitivo bem mais elevado que a visualização de imagens não verbais (vídeos em geral), que, por sua vez, também demandam mais esforço que a leitura de textos escritos de línguas vocais-auditivas. Tais indícios demandam, obviamente, outras pesquisas e aprofundamento das discussões.

Acreditamos, assim, que a modalidade gestual-visual da Libras e a materialidade do texto-fonte - um vídeo, e não um texto escrito - sejam pontos cruciais para que o participante tenha apresentado maior dispêndio de esforço cognitivo no texto-fonte. Apesar de não possuirmos ainda dados ou critérios objetivos que nos permitam comparar o esforço cognitivo despendido na leitura e na tradução de um texto escrito e nessas mesmas atividades em um texto de uma 
língua gestual-visual, acreditamos que, pela materialidade e pela modalidade desse texto, há uma maior demanda cognitiva por parte do tradutor, já que o texto não se encontra disponível de uma só vez na tela. É necessário, para proceder com a compreensão do vídeo e com a produção do texto-alvo, pausas e retornos a trechos já reproduzidos e, portanto, um maior foco de atenção visual por parte do tradutor.

Dois pontos que parecem justificar o maior esforço cognitivo dispendido no texto-fonte são apresentados por Lourenço (2015) e Rodrigues (2018). Lourenço (321) destaca que, pelo fato de a Libras fazer "[...] uso do espaço de sinalização e de movimentos com as mãos e com o corpo para veicular informações de maneira quadridimensional [...]", observações empíricas e relatos de profissionais têm denotado dificuldades encontradas nos processos de tradução de línguas de modalidade gestual-visual para línguas de modalidade vocal-auditiva. O outro argumento é a possível demanda por uma competência tradutória intermodal - entre línguas de diferentes modalidades como a Libras e o português, por exemplo - , competência essa que não aprece ter sido adquirida por P02. Essa competência demandaria do tradutor, segundo Rodrigues (2018), uma capacidade

visual-cognitiva de ler a totalidade das informações gestuais e espaciais, as quais estão expressas quadridimensionalmente por meio da integração [de] [...] dispositivos linguísticos específicos, durante a vocalização [ou escrita do texto-alvo] (habilidades visuais de percepção e interpretação do conjunto de informações gestual e espacialmente codificadas). (Rodrigues 310)

\section{Considerações finais}

Este trabalho teve como objetivo principal desenvolver um estudo exploratório-experimental para investigar aspectos dos proces- 
sos cognitivos envolvidos em uma tarefa de tradução intermodal Libras-português, com distintos perfis de participantes em relação à competência linguística no par em questão e em relação à competência tradutória. Com base nos resultados e discussões aqui desenvolvidos, vem sendo realizada uma pesquisa de maior escopo, com mais participantes e aprofundamento das análises (Zampier, 2019).

No cenário de avanços tecnológicos em estudos de caráter empírico-experimental, tanto na coleta quanto na análise dos dados na pesquisa processual em tradução, é importante ressaltar a tendência de se aplicarem ferramentas metodológicas distintas, mas complementares e de forma articulada, no que se refere ao escrutínio dos processos de percepção, leitura, solução de problemas, produção textual etc., o que corrobora e respalda o princípio de triangulação metodológica de ferramentas de coleta e análise de dados (Alves, 2003). Assim, apoiando-se em diversas pesquisas da área, utilizamos ferramentas como o rastreamento ocular, que permite monitorar com precisão o foco de atenção visual dos participantes, seja em relação à percepção de imagens ou leitura de textos (escritos ou orais em línguas de modalidade gestual-visual ou vocal-auditiva), inferindo eventuais problemas e dificuldades na sua interpretação e possíveis soluções de problemas (Hvelplund, 2017); o registro de inserção de teclado e mouse permite a observação detalhada e em tempo real da produção e edição de textos-alvo (Jakobsen (A)); os protocolos verbais retrospectivos oferecem indícios valiosos para a interpretação sobre os processos de solução de problemas na tradução, evitando a interferência sobre os processos em foco, observada nos protocolos verbais concomitantes (ou TAPS) (Jakobsen (B)); os questionários prospectivos, de conhecimento sobre tradução (PACTE, 2017) e de satisfação foram instrumentos que permitiram traçar o perfil dos participantes e, ainda, avaliar mais alguns aspectos relacionados ao processo de tradução em foco.

Com relação às questões teóricas levantadas neste trabalho, especialmente no que se refere ao esforço cognitivo, observamos que, na tradução de uma língua gestual-visual (Libras) para uma língua vocal-auditiva (português), ainda há poucos dados 
disponíveis na literatura. O trabalho de Wehrmeyer (2014), por exemplo, aponta que a duração média da fixação ocular na leitura de uma língua gestual-visual é bastante superior àquela observada na leitura de um texto escrito em língua vocal-auditiva. $\mathrm{O}$ trabalho de Hvelplund (2017) também demonstra que a duração média da fixação na apreensão de imagens é significativamente superior àquela da leitura de textos escritos, sejam fonte ou alvo, numa tarefa de tradução para a dublagem. O resultado observado neste estudo exploratório converge em relação àqueles trabalhos e demonstra a necessidade de mais pesquisas para que se mapeie com clareza os fatores envolvidos nos processos de tradução intermodal. Verificouse, ainda, uma relativa convergência com os resultados de Jakobsen e Jensen (2008), no que se refere ao perfil do participante cujos dados processuais de rastreamento foram analisados neste trabalho. P02 apresentou maior tempo de fixação, assim como maior número de fixações e duração média de fixação superior na área relativa ao texto-fonte, que, neste caso, tratava-se de um vídeo de sinalização em Libras. Como o participante em questão ainda não tinha um nível de competência linguística suficiente na língua-fonte, esse tipo de resultado tende a ser usual, uma vez que o processo de compreensão do insumo da tradução parece demandar a maior parte do tempo e esforço cognitivo. Com a inclusão futura de dados de outros participantes, com diferentes perfis, espera-se que as hipóteses levantadas possam ser corroboradas, ou seja, que aqueles tradutores com maior competência tradutória e maior competência linguística nas duas línguas apresentem proporcionalmente menos esforço na leitura do texto-fonte que na produção do texto-alvo. De toda forma, é necessário fundamentar de modo mais consistente os parâmetros relativos à leitura de textos em línguas de modalidade gestual-visual, a fim de que se possa discutir e comparar com propriedade as medidas entre as duas modalidades linguísticas.

Observou-se que, no tocante ao conhecimento sobre tradução (PACTE, 2017), ainda é necessário expandir o número de participantes, além de aplicar o questionário aqui utilizado para outros contextos de pesquisa e perfis profissionais e de aprendizes, para 
que se verifique algum tipo de correlação entre a perspectiva de tradução e a competência tradutória. Os resultados aqui alcançados apontam para uma aparente incongruência entre a perspectiva de tradução que seria esperada em um profissional mais experiente e o perfil de competência detectado a partir do questionário prospectivo. Ou seja, os índices encontrados (Índice Dinâmico de Conhecimento sobre Tradução, IDCT, e o Coeficiente de Coerência do Conhecimento sobre Tradução, CCCT) foram menores ou menos satisfatórios para o participante P01, que apresentou um perfil de competência tradutória como TILS mais consolidado. Assim, há que se discutir e investigar em trabalhos futuros a eficácia do instrumento utilizado para a obtenção e análise desse tipo de dado, ou, eventualmente, observar se haveria alguma correlação de tais índices com o perfil de competência tradutória em foco.

Com relação aos níveis de satisfação, verificamos um quadro interessante, em que o participante mais experiente, P01, apresenta uma posição intermediária, com uma satisfação neutra em relação à sua tradução, mas uma satisfação positiva sobre a recepção dessa tradução pelo público; P02 apresenta uma avaliação neutra para os dois itens (satisfação do participante e expectativa do nível de satisfação do público-alvo); já P03 apresenta uma avaliação positiva nos dois casos. A princípio, tais resultados não apontam potenciais correlações com o nível de competência em tradução, mas podem, em um estudo mais abrangente, apontar implicações relevantes não só para a competência tradutória, o perfil de formação acadêmica, a experiência profissional e até para os dados processuais. Tendo em vista o caráter exploratório e relativamente limitado em relação aos dados deste trabalho, não foi possível observar tais implicações e correlações. Entretanto, desenvolvemos algumas reflexões importantes, como, por exemplo, qual seria a relação entre aspectos teóricos e práticos na constituição da competência do tradutor e como desenvolvê-los adequadamente num curso de formação de tradutores de Libras (Zampier e Gonçalves, 2017).

Por fim, constatamos que as pesquisas empírico-experimentais com línguas de sinais ainda são bastante insipientes e raras no con- 
texto acadêmico-científico, com ênfase no par linguístico Libras-português, demonstrando a necessidade de expandirmos e aprofundarmos essa frente de pesquisa, especialmente para fortalecer os estudos descritivos com foco no processo em contextos de tradução intermodal, proporcionando mais dados e eventuais contribuições para a vertente aplicada da didática da tradução nesses contextos.

\section{Referências}

Alves, F. (Ed.). Triangulating translation: perspectives in process-oriented research. Amsterdam/Philadelphia: John Benjamins, 2003.

BRASIL. Decreto-lei no 10.436, de 24 de abril de 2002. Diário Oficial [da] República Federativa do Brasil, Poder Executivo, Brasília, DF, 25 abr. 2002. Seção 1, p. 23.

Emmorey, K.; Thompson, R.; Colvin, R. "Eye gaze during comprehension of American sign language by native and beginning signers". Journal of Deaf Studies and Deaf Education, v. 14, n. 2, p. 237-243, 2009.

Ericsson, K. A.; Simon, H. A. "Verbal reports as data". Psychological Review, v. 87 , n. 3, p. 215-251, 1980.

Hvelplund, K. T. J. (A). Allocation of cognitive resources in translation: an eyetracking and key-logging study. 2011. 260 f. Tese (Doutorado) - Department of International Language Studies and Computational Linguistics, Copenhagen Business School, Copenhagen.

Hvelplund, K. T. J. (B). "Eye tracking and the translation process: reflections on the analysis and interpretation of eye-tracking data". In: Muñoz, R. (Ed.). Minding translation: con la traducción en mente, MonTI Special Issue 1, Universitat d'Alacant, Universitat Jaume I, Universitat de Valencia, (2014): 201-223. 
Hvelplund, K. T. J. (C). "Eye tracking and the process of dubbing translation". In: Díaz-Cintas, J.; Nikolić, K. (Ed.). Fast-forwarding with audiovisual translation. Bristol: Multilingual Matters, 2017:110-125.

Jakobsen, A. L. (A) "Logging target text production with Translog". In: Hansen, G. (Ed.). Probing the process in translation: methods and results, Copenhagen Studies in Language, n. 24. Copenhagen: Samfundslitteratur, p. 9-20, 1999.

Jakobsen, A. L. (B) "Effects of think aloud on translation speed, revision and segmentation". In: Alves, F. (Ed.). Triangulating translation: perspectives in process oriented research. Amsterdam: John Benjamins, 2003, p. 69-95.

Jakobsen, A. L., Jensen, K. T. H. "Eye movement behaviour across four different types of reading task". In: Göpferich, S.; Jakobsen, A. L.; Mees, I. M. (Ed.). Copenhagen Studies in Language, v. 36, p. 103-124, 2008.

Just, M. A.; Carpenter, P. A. "A theory of reading: from eye fixations to comprehension”. Psychological Review, v. 87, n. 4, p. 329-354, 1980

Lourenço, G. "Investigando a produção de construções de interface sintático-gestual na interpretação simultânea intermodal". Cadernos de Tradução, Florianópolis, v. 35, n. 2, p. 319-353, out. 2015. Disponível em: < https://periodicos.ufsc.br/ index.php/traducao/article/view/2175-7968.2015v35nesp2p319/30774> .

O'Brien, S. "Eye tracking in translation-process research: methodological challenges and solutions". In: Mees, I. M.; Alves, F.; Göpferich, S. (Ed.) Methodology, technology and innovation in translation process research. Copenhagen: Samfundslitteratur, 2009. p. 251-266.

PACTE. "Knowledge of translation". In: Hurtado Albir, A. (Ed.). Researching translation competence by PACTE group. Amsterdam: John Benjamins, 2017, p. 131-152.

Pavlović, N.; Jensen, K. T. H. "Eye tracking translation directionality". In: Pym, A.; Perekrestenko, A. (Ed.). Translation Research Projects 2, v. 2. Tarragona: Intercultural Studies Group, 2009. p. 93-109. Disponível em: < http:// www. intercultural.urv.cat/media /upload/domain_317/arxius/TP2/jensenpavlovic.pdf $>$. 
Rodrigues, C. H. "Competência em tradução e línguas de sinais: a modalidade gestual-visual e suas implicações para uma possível competência tradutória intermodal". Trab. linguist. apl., Campinas, v. 57, n. 1, p. 287-318, abr. 2018. Disponível em http://www.scielo.br/scielo.php?script $=$ sci_arttext\&pid $=$ S01031 $8132018000100287 \& \operatorname{lng}=$ pt\&nrm $=$ iso.

Tirkkonen-Condit, S.; Jääskeläinen, R. (Ed.) Tapping and mapping the processes of translation and interpreting. Benjamins Translation Library 37, Amsterdam/ Philadelphia: John Benjamins, 2000.

Wehrmeyer, J. E. "Eye-tracking deaf and hearing viewing of sign language interpreted news broadcasts". Journal of Eye Movement Research 7, v. 1, n. 3, p. 1-16, 2014.

Zampier, P. L. V. O. Uma análise de perfis de competência tradutória e sua influência sobre o processo de tradução no par linguístico Libras-português. 2019. 148 f. Dissertação (Mestrado em Letras: Estudos da Linguagem) - Instituto de Ciências Humanas e Sociais, Universidade Federal de Ouro Preto, Mariana, 2019.

Zampier, P. L. V. O. e Gonçalves, J. L. V. R. Uma análise do desenvolvimento da competência tradutória em cursos superiores de tradução e interpretação de Lingua Brasileira de Sinais (Libras)-português. In: IV Encontro Nacional Cultura e Tradução (ENCULT), 4., 2017, João Pessoa. Anais eletrônicos... João Pessoa: Cultura \& Tradução, 2017. p. 95-105. Disponível em: < http://periodicos.ufpb. br/index.php/ct /article/view/37579/18924>.

Recebido em: 17/03/2019

Aceito em: 08/07/2019

Publicado em: Setembro de 2019

Norma Barbosa de Lima Fonseca. E-mail: normafonseca@gmail.com.

ORCID: http://orcid.org/0000-0002-0207-4789

José Luiz Vila Real Gonçalves. E-mail: zeluizvr@gmail.com

ORCID: https://orcid.org/0000-0002-4669-2677

Pedro Zampier. E-mail: pzampier@gmail.com

ORCID: https://orcid.org/0000-0003-4791-9033 